\title{
AVALIAÇÃO DA EDUCAÇÃO NO BRASIL: A CENTRALIDADE DOS TESTES EM LARGA ESCALA
}

\author{
A. M. F. SILVA, P. I. X. LOPES E A. M. D. A. CASTRO* \\ Universidade Federal do Rio Grande do Norte \\ aldacastro01@hotmail.com*
}

Artigo submetido em agosto/2016 e aceito em setembro/2016

DOI: $10.15628 /$ holos.2016.4939

\section{RESUMO}

A avaliação de políticas educacionais tem se ampliado a partir da adoção do modelo gerencial na gestão pública. Diante desse contexto, teve-se como objetivo analisar a construção dos sistemas de avaliação da educação no Brasil. Como procedimentos metodológicos, utilizou-se da revisão de literatura e da pesquisa documental. O artigo está estruturado em dois momentos. No primeiro, investigou-se a construção do sistema de avaliação da educação básica e, no segundo momento, examinou-se a política de avaliação para a educação superior, com ênfase na graduação. Constatou-se, na educação básica, que tem ocorrido um processo de esvaziamento da autonomia escolar e das autoavaliações diante do destaque que as provas em larga escala estandardizadas têm assumido, especialmente através da Provinha Brasil, da Prova Brasil, da Avaliação Nacional da Alfabetização (ANA), do Exame Nacional do Ensino Médio (ENEM) e do Índice de Desenvolvimento da Educação Básica (IDEB). Na educação superior, os testes aplicados aos alunos, desde o Exame Nacional de Cursos (ENC) ao Exame Nacional de Desempenho dos Estudantes (ENADE), têm assumido centralidade na avaliação desse nível de ensino em detrimento da avaliação institucional mais ampla. Concluiu-se que é preciso desenvolver sistemas de avaliação que entendam a educação como um direito social e dever do Estado e que deem conta da globalidade, a partir de todos os múltiplos elementos que compõem as instituições. Ressaltou-se o papel da autoavaliação, com o intuito de conquistar a valorização da autonomia institucional.

PALAVRAS-CHAVE: Educação básica. Educação superior. Sistemas de avaliação. Testes.

\section{EDUCATIONAL EVALUATION IN BRAZIL: TESTS CENTRALITY ASSUMED BY SURVEY}

\begin{abstract}
The evaluation of educational policies has been expanded with the adoption of the management model in the public context. Through this reality, this paper aims to analyze the construction of the education assessment systems in Brazil. As methodological procedures, was used the literature review and documentary research. The article is structured into two parts. At first, was investigated the construction of the evaluation of the basic education system and, in a second time, was examined the assessment policy for the higher education, with emphasis on graduation. It was found, in the basic education, that has been occurring a process of emptying of school autonomy and self-assessments on the highlight that the tests in large standardized scale have taken, especially through the Provinha Brasil, by Prova
\end{abstract}

Brasil, National Assessment of Literacy (ANA), National High School Exam (ENEM) and by the Development Index of the Basic Education Development (IDEB). In higher education, were applied tests to students, from the National Courses Exam (ENC) to the National Assessment of Students Performance (ENADE) have assumed centrality in assessing this level of education to the detriment of the broader institutional assessment. It is concluded that it is need to develop evaluation systems that understand the education as a social right and a duty of the State and that afford the whole of it, from all the multiple elements that composes the institutions. This article emphasizes the role of the self-assessment, in order to conquer appreciation of the institutional autonomy.

KEYWORDS: Basic education. Higher education. Evaluation systems. Tests. 


\section{INTRODUÇÃO}

As transformações ocorridas, notadamente a partir da segunda metade do século XX, no processo produtivo e o surgimento de uma sociedade global tiveram impacto decisivo na constituição da educação em diversos países, passando a informação e o conhecimento e, por conseguinte, o ensino, a ocuparem papel central no desenvolvimento da economia. Diante desse contexto, organismos internacionais e governos perceberam a necessidade de estender educação básica a todos e, também, criar mecanismos de acesso à formação superior, locus privilegiado para produzir pesquisa, desenvolvimento e inovação.

Ao mesmo tempo, a reconfiguração dos Estados nacionais - incluindo o Brasil -, sob o ideário neoliberal, impulsionou significativas mudanças na administração pública rumo ao modelo gerencial. Um dos pilares foi a redução dos gastos públicos, sobretudo no setor de serviços, abrangendo a educação. Nesse sentido, a partir de uma agenda globalmente estruturada, expandiram-se os sistemas de ensino dos diversos países e, paralelamente, o aparelho de Estado assumiu um novo papel, que se guiou prioritariamente pelo princípio da eficiência, centrado nos resultados e no custo mínimo.

Desse modo, a avaliação de políticas públicas, como uma das formas de prestação de contas, ganhou notoriedade. No campo educacional, estava subjacente a ideia de que as instituições de ensino deveriam justificar o financiamento público através de seu rendimento. A avaliação foi se associando paulatinamente às ideias de accountability, produtividade e gestão racional em conformidade com uma perspectiva economicista. Assim, as mudanças implementadas nos países centrais e periféricos do capitalismo mundial se valeram da avaliação como instrumento legitimador das "(contra)reformas" (LEHER, 2004), que alteraram o modo de organização e gestão. Essas reestruturações políticas e educacionais, apresentadas como "naturais", orientaram-se pela descentralização (especialmente de aspectos administrativos e financeiros) e, simultaneamente, pela regulação. No Brasil, a matriz do "Estado-avaliador" (AFONSO, 2009) foi ajustada na legislação educacional, através da Lei no 9.394/1996, que estabeleceu as diretrizes e bases da educação nacional (LDB). Nesta, entre outros aspectos, definiu-se como incumbência da União "assegurar processo nacional de avaliação do rendimento escolar no ensino fundamental, médio e superior [...]" (Art. 9o, VI).

Diante desse contexto, este artigo tem como objetivo analisar a construção dos sistemas de avaliação da educação no Brasil. Como procedimentos metodológicos, utilizou-se da revisão de literatura e da pesquisa documental.

O artigo está estruturado em dois momentos. No primeiro, investigou-se a educação básica, percebendo o processo de esvaziamento da autonomia escolar e das autoavaliações diante do destaque que as provas em larga escala estandardizadas têm assumido, especialmente a Provinha Brasil, a Prova Brasil, a Avaliação Nacional da Alfabetização (ANA) e o Exame Nacional do Ensino Médio (ENEM). No segundo momento, examinou-se a educação superior, com ênfase na graduação. Notar-se-á que os testes aplicados aos alunos - atualmente através do Exame Nacional de Desempenho dos Estudantes (ENADE) - têm assumido centralidade na avaliação desse nível de ensino em detrimento da avaliação institucional mais ampla. 


\section{AVALIAÇÃO DA EDUCAÇÃO BÁSICA}

A avaliação em larga escala na educação básica, com testes aplicados a um amplo universo de alunos, tem influenciado a vida da escola e as práticas pedagógicas dos seus profissionais, uma vez que a forma de regulação educacional vigente implica na responsabilização dos sujeitos pelo trabalho que desenvolvem. A instância central de poder define o que será avaliado por meio dos Parâmetros Curriculares Nacionais (PCNs), controlando o alcance dos conteúdos mínimos. Assim, "a avaliação externa às escolas possibilita que o controle sobre os serviços educacionais se torne mais fluido, baseado na divulgação de informações que interligam Estado, escola e sociedade [...]", conforme destacam Garcia e Nascimento (2012, p. 96).

No contexto da reforma educacional brasileira, a existência de diferentes sistemas de avaliação da educação básica tem incentivado, em grande medida, o trabalho desenvolvido nas escolas, buscando ajustar o trabalho às demandas atuais de mercado. Dessa forma, na concepção de Garcia e Nascimento (2012, p. 97), a avaliação externa constitui-se

[...] uma forma de controlar os resultados educacionais, responsabilizar os educadores pelos resultados de suas ações, bem como imprimir padrão mínimo de qualidade à ação educativa. [...] os resultados das avaliações nacionais são divulgados para que a população fiscalize o trabalho escolar e avalie a competência dos professores, considerando os resultados obtidos pelos alunos. [...] confere-se maior visibilidade aos atores locais, tornando os gestores, os professores e os funcionários das escolas os responsáveis pelos resultados educacionais, sem que se preste a mesma visibilidade às ações que o Estado deveria empreender para que o trabalho educativo tenha qualidade efetiva.

As escolas de educação básica brasileira têm sido alvo das avaliações em larga escala desde a década de 1990. O Sistema de Avaliação da Educação Básica (Saeb) foi o primeiro sistema de avaliação nacional a ser implantado no Brasil. Segundo Garcia e Nascimento (2012), o Saeb foi orientado por organismos financeiros e internacionais, como o Banco Mundial. Sua construção foi marcada pela participação da camada de professores e de especialistas das Secretarias Estaduais de Educação. Assim, a ampla participação na construção do Saeb culminou na elaboração de objetivos gerais, dando ênfase à melhoria da qualidade da educação.

Na concepção de Garcia e Nascimento (2012, p. 93), o Saeb busca, entre outras medidas, "[...] conferir transparência aos resultados educacionais, responsabilizar os profissionais pelos resultados obtidos e fomentar a competividade entre as escolas por recursos financeiros [...]". A sociedade, por sua vez, mantém o papel de fiscalizadora, na medida em que cobra das instituições os resultados almejados. Assim, como meio de promover o incremento dos resultados, as instituições que obtêm as melhores colocações recebem incentivos financeiros e o reconhecimento social.

Mesmo criado em 1990, foi somente em 1994 que o Saeb foi regulamentado pela Portaria no 1.795, de 27 de dezembro de 1994 e, desde então, vem sendo reestruturado. Em 2005 foi alterado pela Portaria no 931, de 21 de março de 2005 (BRASIL, 2005) passando a ser constituído por dois processos: a Avaliação Nacional da Educação Básica (Aneb) e a Avaliação Nacional do Rendimento Escolar (Anresc). 
A Aneb manteve os aspectos originais do Saeb, tendo como características o fato de ser amostral e de ocorrer a cada dois anos, envolvendo estudantes do 5o e 9o anos do ensino fundamental e 3 ano do ensino médio das escolas públicas e particulares de todo o país. Divulga os resultados educacionais de cada unidade da federação, região e para o Brasil, de forma geral, mas não identificava as escolas e nem seus atores escolares (INEP, 2016).

A Anresc, também conhecida como Prova Brasil, é aplicada aos alunos do 50 e do 90 ano do Ensino Fundamental de todas as escolas públicas, localizadas em áreas urbanas do Brasil, com uma média de mais de 20 alunos matriculados na série. Essa avaliação é quase universal, pois divulga os resultados escolares de forma que cada unidade escolar receba o seu resultado global. São divulgados os resultados e as médias de desempenho nacional das regiões do País, das Unidades da Federação e de cada município e escola participante.

Posteriormente, com base nesses resultados e nos dados do Censo Escolar, é calculado o Índice de Desenvolvimento da Educação Básica (Ideb). Este foi criado em 2007 pelo Instituto Nacional de Estudos e Pesquisas Anísio Teixeira (INEP), como parte do Plano de Metas Compromisso Todos pela Educação, e tem como uma das metas atingir um índice nacional igual a 6,0 nos anos iniciais do ensino fundamental, até 2022. Essa meta é uma tentativa de adequar o patamar educacional brasileiro à média dos países da Organização para Cooperação e Desenvolvimento Econômico (OCDE) (INEP, 2016).

Em meio às modificações, em 2013 o Saeb passou a ser composto, além da Aneb e da Anresc/Prova Brasil, pela Avaliação Nacional da Alfabetização (ANA), regulamentada pela Portaria no 482, de 27 de junho de 2013 (INEP, 2016). Trata-se de uma avaliação censitária e envolve alunos do 3 o ano do Ensino Fundamental de escolas públicas. Tem por objetivo avaliar os níveis de alfabetização e letramento na disciplina de Língua Portuguesa, alfabetização Matemática e condições de oferta do Ciclo de Alfabetização das redes públicas.

Sendo assim, avaliações como as do Saeb e Prova Brasil, baseadas em testes, ou o monitoramento através do IDEB, que considera esses testes, implicam em pressão nos agentes envolvidos no campo educacional e a uma acentuada sujeição da comunidade escolar ao controle externo. Essas provas denotam mudanças nas formas de regulação dos serviços educacionais orientadas pelo mercado, com base no qual se considera que o desdobramento da qualidade educacional é alcançado por meio da publicação dos resultados obtidos pelas instituições e do estímulo à concorrência. Grosso modo, as provas em larga escala se tornam a representatividade última da qualidade educacional, culpabilizando os professores pelo fracasso e ocultando as responsabilidades do Poder Público com o processo de ensino-aprendizagem.

Autores como Freitas (2012) e Souza e Oliveira (2003) apontam que as avaliações nacionais classificatórias têm colaborado para a consolidação das relações de quase-mercado educacional que, distante de auxiliar na construção de um referencial de qualidade capaz de promover o desenvolvimento humano em sua complexidade, vem redundando em prejuízo a esse ideal. Freitas (2012) demonstra que a reforma do sistema público de educação e, em particular, as instituições de sistemas de avaliação nacionais têm trazido consequências, tais como: estreitamento do currículo escolar no qual os professores são induzidos a limitar o ensino a disciplinas e conteúdos abordados nas avaliações; indução da competição por melhores resultados nas provas, diminuindo a possibilidade de cooperação entre si; pressão para que os profissionais apresentem bons resultados, atrelada a bonificações financeiras, levando-os a afastar de suas classes os estudantes 
com dificuldades de aprendizagem e/ou alterar as notas desses alunos; ainda, a pressão por resultados incentiva as escolas a selecionarem seus estudantes ou a segregá-los em turmas separadas.

Diante dessas distorções, é preciso defender um sistema de avaliação que considere os diversos contextos sociais, no qual priorize a participação dos educadores. Um sistema concebido nessa perspectiva tem o papel não só de regular e supervisionar, mas também de promover e contribuir para a melhoria educacional. Dessa maneira, fornece dados que possibilitem a análise do trabalho educativo no interior das instituições, bem como a definição de políticas e ações por parte dos governos. Ou seja, a avaliação deve ser um mecanismo para que os profissionais, de forma empoderada, analisem o próprio trabalho e tenham efetivamente a possibilidade de desenvolver um autoconhecimento, uma autoavaliação.

Quintas e Vitorino (2013) demonstram que, em muitos países europeus, as políticas de avaliação externa se articulam a processos de autoavaliação das instituições. No entanto, não é o que se tem constatado na realidade das escolas brasileiras. Como os estabelecimentos de ensino estão subordinados às políticas macro, as avaliações externas, enquanto instrumento de controle das metas estabelecidas pelo governo, têm restringido a autonomia escolar, exaurindo, dessa maneira, o potencial da autoavaliação.

Defende-se, aqui, todavia, que somente as avaliações externas em si não dão conta das especificidades de cada unidade escolar. Assim,

A autoavaliação institucional como um processo permanente de busca de autoconhecimento da escola, ainda que realizada de forma informal e não sistemática, possibilita de maneira muito mais efetiva o repensar das ações que estão sendo desenvolvidas. [...] a autoavaliação é um instrumento tão necessário para a valorização da autonomia institucional que não deve deixar de desconsiderar o que dizem as avaliações em larga escala. [...] os resultados obtidos nas duas formas de avaliar podem/devem propiciar um diálogo interessante e produtivo para as tomadas de decisão da equipe escolar envolvendo toda a comunidade da escola (HERNANDES; HONDA, 2013, p. 172).

Nesse sentido, é importante que haja um equilíbrio entre as duas formas de avaliar, compreendendo que a ausência de uma pode comprometer ou influenciar os resultados. Ao privilegiar apenas a avaliação externa, corre-se o risco de apenas medir o nível de desempenho dos alunos ou a eficácia escolar, mascarando a verdadeira dinâmica institucional e contribuindo cada vez mais para a perda da autonomia escolar. Na prática, as avaliações em larga escala, especialmente a Provinha Brasil, a Prova Brasil, a ANA e o Exame Nacional do Ensino Médio (ENEM) têm contribuído para essa perda de autonomia escolar, na medida em que essas avaliações não priorizam os processos, mas somente o produto final. Além disso, a forma como são publicados os resultados e a pressão por prestação de contas têm instalado a lógica competitiva entre escolas e entes federados.

Entende-se que um sistema de avaliação deve proporcionar às instituições de ensino a utilização de sua autonomia na definição de projetos próprios de ensino. Dessa forma, "[...] as escolas podem ser caracterizadas como instituições capazes de criar e pensar suas próprias políticas e diretrizes educacionais" (JESUS; MANFIO, 2013, p. 178). Partindo dessa perspectiva, 
julga-se ser possível que as escolas possuam autonomia para recriar e resignificar as suas políticas e ações. Mas, para isso, é necessário reconhecer e promover a autoavaliação institucional.

\section{AVALIAÇÃO DA EDUCAÇÃO SUPERIOR}

Segundo Zandavalli (2009), as primeiras avaliações de conjuntura da educação superior ocorreram nos anos 1960. Essas avaliações, em grande medida, subsidiaram a Lei no 5.540/1968, que fixou a Reforma Universitária. Com o declínio do Governo Militar, as ações avaliativas avançaram, em 1983, a partir do Programa de Avaliação da Reforma Universitária (PARU). Em 1985, a Comissão Nacional para Reformulação da Educação Superior (CNRES), entre outras ideias, vislumbrava como possibilidade uma avaliação comparativa dos formados através de testes padronizados, argumentando que "este é, possivelmente, o melhor indicador de desempenho dos cursos" (MEC, 1985, p. 55). Vale mencionar, ainda, os trabalhos do Grupo Executivo para a Reformulação da Educação Superior (GERES) e o Decreto no 92.200/1985, que instituiu o Programa Nova Universidade, tendo como um dos objetivos a implantação de um sistema de acompanhamento e avaliação das IES. Nenhuma dessas experiências, entretanto, culminou na aplicação concreta de uma avaliação sistemática e contínua.

Não obstante, estava posto no cenário global que as instituições de educação superior (IES) precisavam ser avaliadas, pois era uma matriz em germinação na construção da administração pública gerencial. Faltava, porém, definir no Brasil qual seria o modelo. Em meio ao embate, nos anos 1990, como política pública educacional, ocorreram duas experiências distintas de avaliação institucional no âmbito das IES: a primeira foi o Programa de Avaliação Institucional das Universidades Brasileiras (PAIUB); a segunda, o Exame Nacional de Cursos (ENC-Provão).

A formulação do PAIUB teve início em julho de 1993, no Governo do Presidente Itamar Franco, a partir da criação da Comissão que tinha como objetivo estabelecer diretrizes e viabilizar a implementação do processo de avaliação institucional nas universidades brasileiras. A Comissão publicou, em novembro de 1993, o Documento Básico "Avaliação das Universidades Brasileiras" (BRASIL, 1994), que continha as condições mínimas que precisavam ser atendidas no projeto avaliativo de cada IES. Estava prevista a criação de uma comissão de avaliação no interior de cada instituição, que elaboraria um projeto de autoavaliação, pois um dos princípios era o de que a avaliação é fundamentalmente endógena. A Secretaria de Ensino Superior (SESU/MEC) lançou o Edital convidando as Universidades interessadas a apresentarem projetos para o período de 1994/1995, tendo participado dezenas de IES. Desse modo, o PAIUB foi a primeira tentativa prática de estabelecer um sistema nacional de avaliação institucional da educação superior. $O$ apoio ao Programa foi se enfraquecendo paulatinamente durante o Governo do Presidente Fernando Henrique Cardoso (FHC) a partir de 1995, uma vez que o aparelho estatal, sob o modelo gerencial, passou a exigir prestação de contas sob um movimento exógeno, focada nos resultados. Ademais, a educação passou a ser entendida como serviço não-exclusivo do Estado, ocorrendo simultaneamente um processo de diversificação institucional e mercantilização da educação superior, bem como controle das IES públicas através do contrato de gestão. Dessa maneira, o PAIUB foi desenvolvido por diversas universidades, porém, sem a continuidade do financiamento, foi extinto, sem uma manifestação formal (BARREYRO, ROTHEN, 2006).

Em paralelo, o Governo FHC editou a Medida Provisória no 1.159/1995, posteriormente convertida na Lei no 9.131/1995, criando, assim, o Exame Nacional de Cursos (ENC) - que ficou 
popularmente conhecido como "Provão" - aplicado aos formandos, no período de 1996 a 2003 , com o objetivo de avaliar os cursos de graduação. Até então, nenhuma das propostas ou experiências havia implementado testes aplicados a estudantes como instrumento de avaliação dos cursos ou IES. Estabeleceu-se, dessa maneira, pela primeira vez, que o MEC fizesse avaliações periódicas das instituições e dos cursos de graduação, realizando necessariamente, a cada ano, exames com base nos conteúdos mínimos estabelecidos para cada curso, destinados aos alunos em fase de conclusão, sendo condição prévia para obtenção do diploma. Estava previsto também que o MEC divulgaria, anualmente, o resultado do desempenho de cada curso no exame. Desse modo, embora precedido pelas iniciativas discutidas anteriormente, o ENC-Provão inaugurou a política de avaliação externa em larga escala, através de uma prova estandardizada obrigatória condicionada à expedição de diploma.

Os procedimentos para o processo de avaliação dos cursos e IES foram estabelecidos pelo Decreto no 2.026/1996. Embora citasse diversos procedimentos, o ENC-Provão foi o instrumento de avaliação privilegiado, visto que "[...] os outros tinham menor destaque na divulgação oficial, sendo os seus resultados utilizados para efeitos regulatórios no reconhecimento de cursos de graduação." (BARREYRO; ROTHEN, 2006, p. 959). Conforme Rothen e Schulz (2007, p. 169), o ENCProvão "[...] foi o instrumento quase exclusivo, tanto que o resultado dessa avaliação era amplamente divulgado, o que não sucedia com o resultado das outras avaliações.". Em última instância, não avaliava efetivamente a aprendizagem; apenas media desempenhos em uma dada circunstância. Assim, de uma perspectiva de avaliação institucional e processual, que estava sendo construído pelo PAIUB, chegou-se a uma avaliação com ênfase nos resultados de exames. Sem destacar o processo de aprendizagem e as condições institucionais, o ENC-Provão limitou-se à mensuração do resultado final através de uma prova.

Como pano de fundo, tinha-se a (contra)reforma ${ }^{1}$ do aparelho do Estado, desenvolvida a partir de 1995, que incorporou formalmente o modelo gerencial na administração pública brasileira. Por conseguinte, houve uma "gerencialização" (FARIA, 2005) da avaliação de políticas públicas decorrente da sua instrumentalização no processo de reorganização do Estado. Sob a racionalidade do mundo econômico, evidenciaram-se os resultados e guiou-se pelo princípio da eficiência individual, prevalecendo uma avaliação orientada prioritariamente para a quantificação, mensuração, comparação, seleção e controle.

O ENC-Provão foi alvo de resistência e boicotes, sobretudo da comunidade acadêmica. Esse fato demonstra que o campo da avaliação é uma condensação de um equilíbrio de forças representadas, conforme Maués (2003), por um lado oficial (Governo) e, por outro, dos movimentos sociais e sindicais. Para a autora, esses dois grupos travaram embates em várias instâncias, sendo, porém, a convergência de forças favorável ao Governo. Não obstante, os movimentos sociais continuavam lutando por uma proposta alternativa.

Assumindo o discurso de oposição, a Coligação Lula Presidente, na campanha eleitoral de 2002 , criticava o controle centralizador do governo federal e o modelo das avaliações. O Programa de Governo afirmava que a avaliação não deveria servir para a competição entre as universidades,

\footnotetext{
${ }^{1}$ Leher (2004) observa que é recorrente o uso do termo "reforma" na literatura. No entanto, diferentemente do sentido etimológico que a palavra carrega, não existe necessariamente uma conotação positiva. Assim, opta-se pelo elemento de composição "contra" por se tratar de "contra-revolução", que assume aspectos conservadores, embora se apresente como progressista. Isto é, o acréscimo do "contra" é para evitar que regressões e retrocessos passem a representar "reformas" ou "revoluções".
} 
mas sim como instrumento para o planejamento e a intervenção do Estado (COLIGAÇÃO LULA PRESIDENTE, 2002). Para a educação superior, o documento, entre outras propostas, apresentava a revisão do ENC-Provão com o intuito de criar um sistema nacional de avaliação institucional a partir, entre outras, da experiência do PAIUB. Vale salientar que a ideia de um amplo e diversificado sistema de avaliação interna e externa já estava posta na Lei no 10.172/2001, que aprovou o Plano Nacional de Educação (PNE 2001-2010).

Após quatro meses do Governo Lula, foi criada a Comissão Especial de Avaliação da Educação Superior (CEA), que tinha como finalidade analisar, oferecer subsídios, fazer recomendações, propor critérios e estratégias para a reformulação dos processos e políticas de avaliação da educação superior e elaborar a revisão crítica dos seus instrumentos, metodologias e critérios utilizados. Ao término dos debates e audiências públicas, a Comissão apresentou, em agosto de 2003, o documento "Sistema Nacional de Avaliação da Educação Superior (SINAES): bases para uma nova proposta da educação superior" (CEA, 2009). Quanto ao desenho e operacionalização do SINAES, o documento da CEA elencou diversos instrumentos que, articulados, o constituiriam. $O$ aspecto principal era o fato de que a avaliação institucional seria o instrumento central, organizador da coerência do conjunto, sendo constituída pelo processo de autoavaliação e complementada pela avaliação externa - ideia muito semelhante ao que foi proposto no PAIUB. Sob o princípio da globalidade, a avaliação institucional, tanto na dimensão interna, quanto na externa, incorporaria as informações e os resultados de outros instrumentos, tais como o Censo da Educação Superior, o Cadastro das IES, a avaliação da Pós-Graduação, e, ainda, um novo instrumento - em substituição ao ENC-Provão - o Processo de Avaliação Integrada do Desenvolvimento Educacional e da Inovação da Área (PAIDEIA). Este seria aplicado a grupos amostrais de estudantes, em diferentes momentos do percurso da graduação (de meio e de fim de curso). O objetivo era realizar um acompanhamento longitudinal das ações pedagógicas e proceder a análises sobre a evolução dos processos educativos em cada área do conhecimento, percebendo suas relações com a totalidade, especialmente nos aspectos de formação e de inovação.

Observando o conteúdo geral, Lopes e Souza (2014) apontam que o SINAES concebido pela CEA teve como fundamento os princípios e valores de educação superior como bem público. A proposta da CEA situava-se mais próximo de uma perspectiva formativa e democrática, aproximando-se em muitos aspectos do PAIUB. Cabral Neto (2009, p. 35), porém, aponta que:

[...] os estudos da comissão forneceram apenas referências genéricas para o delineamento da nova sistemática de avaliação e que a ideia de avaliação emancipatória, fortemente presente nas recomendações do estudo da comissão, não se materializou na proposta final do modelo avaliativo concebido pelo governo, que se configurou com enfoque no controle e na regulação [...]

Dessa forma, o entrechoque de concepções mutuamente contraditórias, que norteou o processo de formulação, deu outro formato ao SINAES. Segundo Rothen (2006), o processo de discussão no MEC foi marcado por conflitos em relação à função prioritária da avaliação. Nesse debate, o Ministro da Educação Cristovam Buarque apresentou, no início de dezembro de 2003, a proposta de criação do Índice de Desenvolvimento do Ensino Superior (IDES), destinado a avaliar os cursos, e a encaminhou em forma de projeto de lei ao Congresso Nacional. A ideia seria aplicar duas provas aos alunos: uma no primeiro ano do curso e outra no último. Sem uma ampliação do 
debate acerca da proposta de Cristovam Buarque, foi publicada a Medida Provisória (MPv) no 147/2003, instituindo o Sistema Nacional de Avaliação e Progresso do Ensino Superior (SINAPES). $\mathrm{Na}$ exposição de motivos, o Ministro afirmava que o SINAPES introduzia uma avaliação mais rigorosa, apoiado em quatro pilares: o processo de ensino; o processo de aprendizagem; a capacidade institucional; e a responsabilidade do curso com a sociedade em geral. Para cada um desses itens seria construído um indicador parcial. Combinados, esses quatro indicadores comporiam o IDES.

Em janeiro de 2004, com a reforma ministerial, Tarso Genro assumiu o MEC. Após essa troca de ministros, houve debates na Comissão Mista do Congresso Nacional acerca da MPv, com aprovação parcial, integral e rejeição de emendas. Por fim, o conteúdo da MPv no 147/2003 foi significativamente alterado, aprovado no Congresso Nacional sob a Lei no 10.861 e sancionado pelo presidente Lula em 14 de abril de 2004. Tinha-se, assim, pela primeira vez na história das políticas para a educação superior, a formalização de um sistema de avaliação, que articulava um conjunto amplo de instrumentos.

A Lei do SINAES, resultado da síntese complexa dos antecedentes descritos, estabeleceu, entre outros aspectos, que a avaliação das IES (Art. 3ㅇ, § 3ㅇ) ), dos cursos de graduação (Art. 4ㅇ, § 20) e do desempenho dos alunos de cada curso no Exame Nacional de Desempenho dos Estudantes (ENADE) (Art. 5ㅇ, § 8ㅇ), resultaria na aplicação de conceitos, ordenados em uma escala com cinco níveis. Isso abriu possibilidades para classificações e o surgimento de rankings.

Reformulando o PAIDEIA proposto pela CEA, que possuía um caráter educativo e uma concepção formativa que propiciaria elementos de reflexão e análises, sem a conotação competitiva, a Lei do SINAES dispõe sobre o ENADE, que "[...] aferirá o desempenho dos estudantes em relação aos conteúdos programáticos previstos nas diretrizes curriculares do respectivo curso de graduação [...]". (Art. 5요 $\S 1$ ㅇ). Na proposta do PAIDEIA, o exame seria aplicado a grupos amostrais de estudantes, em diferentes momentos do percurso dos estudantes. Já o ENADE é aplicado aos alunos de todos os cursos de graduação, ao final do primeiro e do último ano de curso (Art. 5o, § 2ㅇ), mas, como se tornou facultativo o uso de procedimentos de amostragem, desde 2009 o exame passou a ser censitário. Para Barreyro e Rothen (2006, p. 966), o processo de criação de uma prova em larga escala aplicada aos estudantes, desde o ENC-Provão até o ENADE, foi se constituindo como uma colcha de retalhos. "No fim, persiste a avaliação do produto educação, apesar das críticas sucessivas, o que nos conduz às 'condicionalidades' das agências internacionais de empréstimo". Estabeleceu-se, ainda, na Lei, o princípio meritocrático com base nos conceitos. Foi fixado: "Aos estudantes de melhor desempenho no ENADE o Ministério da Educação concederá estímulo, na forma de bolsa de estudos [...]" (Art. 5o, § 10).

Em 2008, foram instituídos o Conceito Preliminar de Cursos (CPC) para fins dos processos de renovação de reconhecimento de curso - regulamentado pela Portaria Normativa MEC no 4/2008 - e o Índice Geral de Cursos (IGC) das IES - instituído pela Portaria Normativa MEC no 12/2008. O CPC, um indicador prévio da situação dos cursos de graduação, é a tentativa de incorporar ao processo de avaliação da educação superior critérios ditos "objetivos" de qualidade e excelência dos cursos. O CPC vai de 1 a 5 e é divulgado anualmente, junto com os resultados do ENADE. Cursos que obtêm CPC 1 e 2 são automaticamente incluídos no cronograma de visitas dos avaliadores do INEP. Conceito igual ou maior que 3 representa os cursos que atendem aos critérios de qualidade para funcionar; sendo assim, eles podem optar por não receber a visita dos avaliadores e, desse modo, transformar o CPC em conceito permanente. Já os cursos com conceito 
4 e 5 são os de excelência, devendo ser vistos como referência pelos demais. O conceito permanente serve como referência para subsidiar o processo de regulação. O CPC é composto por: a) Desempenho dos concluintes no ENADE; b) Desempenho dos ingressantes no ENADE; c) Indicador de Diferença entre os Desempenhos Observado e Esperado (IDD); d) Qualidade do corpo docente; e) Infraestrutura escolar e organização didático-pedagógica. Chama a atenção o fato de as três primeiras medidas serem realizadas através do ENADE.

Dessa maneira, percebe-se um movimento de retorno à redução do processo de avaliação tendo como primazia os testes, como ocorria no ENC-Provão. Na proposta da CEA, tinha-se a avaliação institucional como foco; a educação transcendia o desempenho estudantil em provas, buscando significados mais amplos da formação humana integral e pondo em relevância a responsabilidade social das IES. Na Lei no $10.861 / 2004$, teve-se como modelo do SINAES os três eixos: avaliação das IES, dos cursos de graduação e do desempenho de seus estudantes. Com o CPC, prioriza-se especialmente os exames em larga escala aplicados aos estudantes como elemento definidor de qualidade de um determinado curso ou IES.

O outro índice, o IGC, é um referencial orientador das comissões de avaliação institucional. Conforme o artigo 2ㅇ da Portaria Normativa do MEC n 12/2008, o IGC é calculado com base na: a) média ponderada dos CPC, sendo a ponderação determinada pelo número de matrículas em cada um dos cursos de graduação correspondentes; e b) média ponderada das notas dos programas de pós-graduação, obtidas a partir da conversão dos conceitos fixados pela CAPES, sendo a ponderação baseada no número de matrículas em cada um dos cursos ou programas de pós-graduação stricto sensu correspondentes. Nas instituições sem cursos ou programas de pósgraduação avaliados pela CAPES, entretanto, o IGC é calculado somente por meio da média ponderada dos CPC.

O CPC e o IGC, buscam concentrar, num único momento, informações de um único aspecto do SINAES, as informações sobre os cursos e a IES, classificando-os e tendo como resultado um ranqueamento. Não obstante o SINAES e o ENADE terem sido concebidos de forma a evitar classificações e punições, em setembro de 2008, o próprio MEC divulgou um ranking (BRITO, 2008). Cabral Neto (2009, p. 47) observa também que "[...] o ENADE tem assumido maior destaque no conjunto do processo de avaliação do Sinaes, tendo sido, inclusive, utilizado como forma de classificar as instituições.".

Mais recentemente, a Lei no 13.005/2014 aprovou o Plano Nacional de Educação (PNE 2014-2024). A meta 13, que trata da educação superior, apresenta como uma das estratégias “13.2) ampliar a cobertura do Exame Nacional de Desempenho de Estudantes - ENADE, de modo a ampliar o quantitativo de estudantes e de áreas avaliadas no que diz respeito à aprendizagem resultante da graduação" (BRASIL, 2014). Ou seja, põe-se como plano de Estado a expansão e intensificação do ENADE.

Registre-se ainda a tramitação, na Câmara dos Deputados, do Projeto de Lei no 4.372/2012 do Poder Executivo, que propõe a criação do Instituto Nacional de Supervisão e Avaliação da Educação Superior (INSAES), que implicará em mudanças na estrutura do SINAES. Caso aprovado, esse órgão será uma autarquia responsável pelas atividades referentes à avaliação e supervisão das IES e cursos de graduação no sistema federal de ensino. Está subjacente a intenção de criar um órgão técnico, eficiente e com poder para atuar sobre a mercantilização da educação, em que cada vez mais "instituições-empresas" buscam mais lucro. Ao que tudo indica, além da ênfase no ENADE 
- que continuará sob a responsabilidade do INEP -, o INSAES intensificará o destaque conferido à avaliação externa, que constituirá referencial para os processos de regulação e supervisão, para fins de emissão dos atos regulatórios de autorização, reconhecimento e renovação de reconhecimento dos cursos de graduação e credenciamento e recredenciamento de instituições.

\section{CONSIDERAÇÕES FINAIS}

A avaliação se constitui em um instrumento importante para a conquista da melhoria educacional, pois possibilita a coleta de informações que podem ser utilizadas para superar dificuldades e construir uma educação com qualidade socialmente referenciada. Nesse sentido, a avaliação implica enfrentar os desafios postos pela realidade com a participação de toda comunidade escolar e universitária.

Constatou-se, entretanto, que tanto na educação básica, como na educação superior, tem ocorrido uma ação desmobilizadora por parte do Governo Central, que toma a avaliação como processo fundamentalmente mercadológico e regulatório, esvaziando a dimensão formativa e democrática da autoavaliação. Os sistemas de avaliação educacional no Brasil, que possuem o potencial de dar conta de múltiplas dimensões institucionais, têm realçado sobretudo os testes aplicados aos estudantes como retrato da qualidade do ensino. Na educação básica, dá-se atualmente relevância à Provinha Brasil, à Prova Brasil, à ANA e ao IDEB. Na educação superior, durante o Governo FHC, ganhou destaque o ENC-Provão e, nos Governos do Partido dos Trabalhadores (PT), o ENADE, o CPC e o IGC.

Essa política converge para o modelo gerencialista vigente na administração pública brasileira, centrado em metas definidas pelos órgãos centrais ou pela pressão do mercado concorrencial. Esta é mais visível no âmbito das IES privadas, algumas de capital aberto, em que a lógica estritamente empresarial tem predominado, com a fixação de metas por parte dos investidores que mantêm as instituições.

É preciso, todavia, desenvolver sistemas de avaliação que entendam a educação como um direito social e dever do Estado e que deem conta da globalidade, a partir de todos os múltiplos elementos que compõem as instituições. Nesse sentido, sem rejeitar a avaliação externa, deve-se ampliar a ênfase dos procedimentos e instrumentos de avaliação para além dos atualmente praticados, incorporando aos processos avaliativos todos os sujeitos e segmentos envolvidos, todas as dimensões e instâncias institucionais.

Desse modo, é necessário resgatar o papel da autoavaliação, com o intuito de conquistar a valorização da autonomia institucional. A avaliação interna e a externa, contemplando a análise global e a participação dos segmentos envolvidos e da sociedade civil, devem ser consideradas. Assim sendo, reduzir-se-á o risco de mascarar o cenário das condições e desenvolvimento educacionais.

\section{REFERÊNCIAS BIBLIOGRÁFICAS}

1. AFONSO, Almerindo Janela. Avaliação educacional: regulação e emancipação: para uma sociologia das políticas avaliativas contemporâneas. 4. ed. São Paulo: Cortez, 2009.

2. BARREYRO, Gladys Beatriz; ROTHEN, José Carlos. "SINAES" contraditórios: considerações 
sobre a elaboração e implantação do Sistema Nacional de Avaliação da Educação Superior. Educação \& Sociedade, Campinas, v. 27, n. 96, p. 955-977, out. 2006.

3. BRASIL. Lei $n$ - 9.131, de 24 de novembro de 1995. Altera dispositivos da Lei $n=4.024$, de 20 de dezembro de 1961, e dá outras providências. Diário Oficial da União, Brasília, 25 nov. 1995. Disponível em: <http://www.planalto.gov.br/ccivil_03/leis/L9131.htm>. Acesso em: 25 jul. 2016.

4. BRASIL. Lei no 9.394, de 20 de dezembro de 1996. Estabelece as diretrizes e bases da educação nacional. Diário Oficial da União, Brasília, 23 dez. 1996. Disponível em: <http://www.planalto.gov.br/ccivil_03/leis/L9394.htm>. Acesso em: 25 jul. 2016.

5. BRASIL. Lei no 10.172, de 9 de janeiro de 2001. Aprova o Plano Nacional de Educação e dá outras providências. Diário Oficial da União, Brasília, 10 jan. 2001. Disponível em: <http://www.planalto.gov.br/ccivil_03/leis/leis_2001/l10172.htm>. Acesso em: 25 jul. 2016.

6. BRASIL. Lei no 10.861, de 14 de abril de 2004. Institui o Sistema Nacional de Avaliação da Educação Superior - SINAES e dá outras providências. Diário Oficial da União, Brasília, 15 abr. 2004. Disponível em: <http://www.planalto.gov.br/ccivil_03/_ato20042006/2004/lei/l10.861.htm>. Acesso em: 25 jul. 2016.

7. BRASIL. Lei no 13.005 , de 25 de junho de 2014. Aprova o Plano Nacional de Educação - PNE e dá outras providências. Diário Oficial da União, Brasília, 26 jun. 2004. Disponível em: <http://www.planalto.gov.br/ccivil_03/_ato2011-2014/2014/lei/l13005.htm>. Acesso em: 25 jul. 2016.

8. BRASIL. Medida Provisória no 147, de 15 de dezembro 2003. Institui o Sistema Nacional de Avaliação e Progresso do Ensino Superior e dispõe sobre a avaliação do ensino superior. Diário Oficial da União, Brasília, 16 dez. 2003. Disponível em: <http://www.planalto.gov.br/ccivil_03/mpv/Antigas_2003/147.htm>. Acesso em: 25 jul. 2016.

9. BRASIL. Projeto de Lei no 4.372, de 31 de agosto de 2012. Cria o Instituto Nacional de Supervisão e Avaliação da Educação Superior - INSAES, e dá outras providências. Brasília, 31 ago. $2012 . \quad$ Disponível em: <http://www.camara.gov.br/proposicoesWeb/fichadetramitacao?idProposicao=554202>. Acesso em: 25 jul. 2016.

10. BRASIL. Secretaria de Ensino Superior. Programa de Avaliação Institucional das Universidades Brasileiras. Brasília: SESu, 1994.

11. BRITO, Márcia Regina F. de. O SINAES e o ENADE: da concepção à implantação. Avaliação: Revista da Avaliação da Educação Superior, Sorocaba, v. 13, n. 3, p. 841-850, nov. 2008.

12. CABRAL NETO, Antonio. Avaliação do ensino superior no Brasil: as tensões entre emancipação e regulação. In: CHAVES, V. L. J.; CABRAL NETO, A.; NASCIMENTO, I. V. (Org.). Políticas para a educação superior no Brasil: velhos temas e novos desafios. São Paulo: Xamã, 2009.

13. CEA. Comissão Especial de Avaliação. SINAES - Sistema Nacional de Avaliação da Educação Superior: bases para uma nova proposta de avaliação da educação superior brasileira. In: INEP. SINAES - Sistema Nacional de Avaliação da Educação Superior: da concepção à regulamentação. 5. ed. Brasília: INEP, 2009.

14. COLIGAÇÃO LULA PRESIDENTE. Caderno Temático do Programa de Governo: Uma Escola do 
Tamanho do Brasil. São Paulo: Comitê Lula Presidente, 2002.

15. FARIA, Carlos Aurélio Pimenta de. A política da avaliação de políticas públicas. Revista Brasileira de Ciências Sociais, São Paulo, v. 20, n. 59, p. 97-109, out. 2005.

16. FREITAS, Luís Carlos et al. Os reformadores empresariais da educação: da desmoralização do magistério à destruição do sistema público de educação. Educação e Sociedade, Campinas, v. 33, n. 119, abr/jun. 2012.

17. GARCIA, Luciane Terra dos Santos; NASCIMENTO, Lenilton Batista do. O Estado-avaliador e a construção do Sistema Nacional de Avaliação da Educação Básica (Saeb). In: CASTRO, Alda Maria Duarte Araújo; FRANÇA, Magna (orgs.). Política Educacional: contextos e perspectivas da educação brasileira. Brasília: Líber Livro, 2012.

18. HERNANDES, Elianeth Dias Kanthack; HONDA, Jacqueline Lima. O trio gestor e as avaliações educacionais no cotidiano escolar. In: OLIVEIRA, Maria Eliza Nogueira (Org.). Gestão escolar e políticas públicas educacionais: um embate entre o prescrito e o real. 1. ed. - Curitiba: Appris, 2013. 224p.

19. INEP. Instituto Nacional de Estudos e Pesquisas Educacionais Anísio Teixeira. Educação básica. Saeb. Avaliação Nacional da Educação Básica - ANEB. Disponível em: <http://www.inep.gov.br/basica/saeb/prova_brasil/inf_produzidas.htm>. Acesso em: 02 maio 2016.

20. INEP. Educação básica. Saeb. Avaliação Nacional do Rendimento Escolar - ANRESC. Disponível em: <http://www.inep.gov.br/basica/saeb/prova_brasil/inf_produzidas.htm>. Acesso em: 02 maio 2016.

21. INEP. Educação básica. Saeb. ENEM. Sobre o Enem. Disponível em: <http://www.inep.gov.br/basica/saeb/prova_brasil/inf_produzidas.htm>. Acesso em: 29 jul 2016.

22. INEP. Educação básica. Saeb. A Avaliação Nacional da Alfabetização - ANA. Disponível em: <http://www.inep.gov.br/basica/saeb/prova_brasil/inf_produzidas.htm>. Acesso em: 02 maio 2016.

23. JESUS, Graziela de; MANFIO, Aline. Avaliação em larga escala, gestão e qualidade de ensino: vivências e concepções dos gestores de escolas estaduais. In: OLIVEIRA, Maria Eliza Nogueira (Org.). Gestão escolar e políticas públicas educacionais: um embate entre o prescrito e o real. 1. ed. Curitiba: Appris, 2013. 224p.

24. LEHER, Roberto. Prefácio: a (contra-)reforma universitária do governo Lula e o fim das fronteiras entre o público e o privado. In: NEVES, L. M. W. (Org.). Reforma universitária do governo Lula: reflexões para o debate. São Paulo: Xamã, 2004.

25. LOPES, Pedro Isaac Ximenes; SOUZA, Lincoln Moraes de. Avaliação política e meta-avaliação do Sistema Nacional de Avaliação da Educação Superior (SINAES). In: SOUZA, L. M. de (Org.). Avaliações e reflexões sobre políticas públicas de assistência social, saúde e educação. Natal: EDUFRN, 2014..

26. MAUÉS, Olgaíses Cabral. A avaliação institucional: uma política para o ensino superior. Universidade e Sociedade, Brasília, ano 13, n. 30, p. 110-118, jun. 2003.

27. MEC. Ministério da Educação. Comissão Nacional para Reformulação da Educação Superior. Uma nova política para a educação superior: relatório final. Brasília, 1985. 
28. MEC. Ministério da Educação. Portaria Normativa no 12, de 5 de setembro de 2008. Institui o Índice Geral de Cursos da Instituição de Educação Superior (IGC). Brasília, 5 set. 2008. Disponível em: <http://download.inep.gov.br/download/superior/condicoesdeensino/PORTARIA_NORMATI VA_12.pdf>. Acesso em: 25 jul. 2016.

29. MEC. Ministério da Educação. Portaria Normativa no 4, de 5 de agosto de 2008. Regulamenta a aplicação do conceito preliminar de cursos superiores. Brasília, 6 ago. 2008. Disponível em: $<$ http://portal.mec.gov.br/index.php?option=com_docman\&view=download\&alias=670sesu-port-04-2008-pdf\&Itemid=30192>. Acesso em: 25 jul. 2016.

30. MEC. Portaria n. 931, de 21 de março de 2005. Institui o Sistema de Avaliação da Educação Básica - SAEB, que será composto por dois processos de avaliação: a Avaliação Nacional da Educação Básica - ANEB, e a Avaliação Nacional do 12 Rendimento Escolar - ANRESC. Diário Oficial da União. Brasília, seção 1, n. 55, p. 17, mar. 2005.

31. QUINTAS, Helena (Org.); VITORINO, Teresa. Escolas e avaliação externa: um enfoque nas estruturas organizacionais. 1. ed. Lisboa. Editora Mundos Sociais, 2013.

32. ROTHEN, José Carlos; SCHULZ, Almiro. SINAES: Do documento original à legislação. Revista Diálogo Educacional, Curitiba, v. 7, n. 21, p. 163-180, maio/ago. 2007.

33. ROTHEN, José Carlos. Ponto e contraponto na avaliação institucional: análise dos documentos de implantação do SINAES. In: SILVA JUNIOR, J. dos R.; OLIVEIRA, J. F. de; MANCEBO, D. (Org.). Reforma universitária: dimensões e perspectivas. Campinas: Alínea, 2006.

34. SOUZA, Zákia Lian; OLIVEIRA, Romualdo Portella. Políticas de avaliação da educação e quase-mercado no Brasil. Educação e Sociedade, Campinas, v.24, n. 84, set. 2003.

35. ZANDAVALLI, Carla Busato. Avaliação da educação superior no Brasil: os antecedentes históricos do SINAES. Avaliação: Revista da Avaliação da Educação Superior, Sorocaba, v. 14, n. 2, p. 385-438, jul. 2009. 